\title{
Los historiadores y la prostitución. Un balance historiográfico relativo a la etapa contemporánea
}

\author{
Historians and Prostitution. A Historiographical Evaluation relating \\ to Modern Age
}

\author{
ISABEL ESCOBEDO MUGUERZA \\ Universidad de Zaragoza \\ iescobedo@unizar.es
}

Resumen: La prostitución ha generado históricamente, y genera, numerosos debates en torno a su forma de organización y regulación. Sin embargo, las distintas investigaciones históricas no le han prestado especial atención dejando, en muchas ocasiones, este campo a los historiadores del derecho y la medicina. En los últimos años, y contando con los estudios pioneros de Jean Louis Guereña, la tendencia parece estar invirtiéndose y otorgándole a la sexualidad, y con ella a la prostitución, un papel central.

Palabras clave: prostitución, abolicionismo, reglamentarismo, higienismo, sexualidad.

Abstract: Prostitution has historically generated, and generates, a huge amount of debates around its organization and regulation. However, different historical researches have not paid special attention to it, leaving this field to the historians of law and medicine in many occasions. In recent years, in addition to the pioneering studies of Jean Louis Guereña, the trend seems to be reversing and giving sexuality, and with it prostitution, a crucial role.

Keywords: Prostitution, abolitionism, reglamentarism, hygienists doctors, sexuality.

\section{Introducción}

A pesar de la relevancia de la prostitución ${ }^{1}$ para los discursos sobre la organización de lo social y la construcción de las identidades de género, el tema ha sido abordado de

\footnotetext{
${ }^{1}$ En este trabajo vamos a entender la prostitución como la institución social que supone el intercambio puntual de servicios sexuales por dinero que realizaban algunas mujeres, estigmatizadas y discriminadas
}

Recibido: 26 de agosto de 2018; aceptado: 1 de marzo de 2019; publicado: 30 de septiembre de 2019.

Revista Historia Autónoma, 15 (2019), pp. 155-170

e-ISSN: 2254-8726; DOI: https://doi.org/10.15366/rha2019.15.008 
forma insuficiente por la historiografía, sobre todo en el caso español. Como se podrá observar a lo largo de este artículo, los historiadores han dejado este campo de estudio en manos de los historiadores del derecho (reglamentación y leyes referentes en el tema) o en la de los historiadores de la medicina (relación de la misma con las enfermedades venéreas y la lucha contra ellas), los cuales, sin duda, son los campos más estudiados y abordados por las distintas investigaciones.

No obstante, en la actualidad, se han reavivado los distintos debates en torno a la prostitución, lo que parece estar despertando el interés de los investigadores y, con ello parece que se está comenzando a revertir la tendencia antes señalada. En este sentido, se está desarrollando en el seno de muchos países occidentales un profundo debate en torno a la prostitución y, especialmente, a su regulación. Los motivos que se exponen para pedir la vuelta de los reglamentos son aquellos que motivaron su implantación hace siglo y medio: la moral, el orden público y la salud pública (el SIDA en nuestro caso). Estos, si contemplamos la historia, no son en absoluto novedosos ${ }^{2}$.

En este sentido, y para poder comprender este estado de la cuestión, es fundamental tener claros los distintos debates y formas de organización jurídica que ha sufrido la prostitución a lo largo del tiempo ya que, en torno a ellos, girarán las investigaciones de los principales autores. Así pues, encontramos en el pasado tres actitudes o posturas respecto a este fenómeno ${ }^{3}$. En primer lugar, nos encontramos con los prohibicionistas. Estos apostaban por un sistema mediante el cual la prostitución quedaba prohibida y castigada con la cárcel. Este fue, a todos los efectos, el marco normativo existente en España entre 1623 y 1845. En segundo lugar, se sitúan los reglamentaristas. Estos defendían que la prostitución no debía ser proscrita, sino que era necesaria su regulación mediante textos legales. Su opinión partía de la presunción de que la prostitución constituía un "mal social" inevitable, por tanto, para lograr el "bien común" y evitar pecados y excesos mayores era necesaria su contención. Este sistema ya había estado presente en España durante toda la Edad Media y parte de la Edad Moderna, sin embargo, en relación con la historia contemporánea, será el método adoptado entre 1845 y 1935. Así mismo, también será el sistema que adoptará el franquismo entre 1941 y 1956. En tercer y último lugar, nos encontramos con el abolicionismo. Los defensores de esta opción, salidos del movimiento

por ello. En segundo lugar, vamos a hacer referencia a la prostitución femenina adulta. Tampoco se tratará la prostitución masculina ya que se trata de un tema que aún ha sido menos tratado por la historiografía.

${ }^{2}$ Aunque este trabajo va a hacer referencia a los diferentes trabajos que los historiadores han realizado y que abarcan un arco cronológico comprendido entre finales del siglo XVIII y los años finales del franquismo, si alguien estuviera interesado en los debates actuales, sería imprescindible la lectura de algunas autoras como Amelia Valcárcel (por ejemplo, “La prostitución es un modo de vida deseable?”, en El País, 21 de mayo de 2007. «http://www.elpais. com/articulo/opinion/audiovisual/calidad/democrática/elpeiopi/20110709elpepiopi 5/Tes》" [Consultado el 24 de febrero de 2019]) o Ana de Miguel (Neoliberalismo sexual. El mito de la libre elección, Madrid, Cátedra, 2015). También es muy provechosa la lectura del libro de Gimeno, Beatriz, La prostitución, Barcelona, Ediciones Bellaterra, 2012.

${ }^{3}$ Para una visión global que analice las concepciones sobre la sexualidad y las mujeres en los siglos XIX y XX mantenidas por el pensamiento vanguardista y el progresismo, desde la filosofía feminista, resulta fundamental el trabajo de Puleo, Alicia H., Dialéctica de la sexualidad. Género y sexo en la filosofía contemporánea, Madrid, Cátedra, 1992. 
feminista inglés (1869), nacerán como los claros opositores del sistema reglamentarista. Proponían el fin de la reglamentación y la integración de las prostitutas en un mercado laboral que les diera más oportunidades para subsistir (escasos salarios femeninos). Este será el sistema implantado por el decreto del 28 de junio de 1935 durante la II República.

Así pues, y entrando ya en materia, hasta bien entrado el siglo xx, el único estudio de conjunto disponible sobre la historia de la prostitución en España era el de Enrique Rodríguez Solís ${ }^{4}$, publicado en 1892 y 1893 en dos volúmenes respectivamente. Aunque el cambio de tendencia llegará en 1974 con la publicación de la tesis de Carmen del Moral ${ }^{5}$, habrá que esperar a la década de los ochenta para disponer a la vez de estudios primarios serios y de ámbito local en los que los historiadores reflejaban la riqueza de los archivos municipales para la historia de la prostitución y de algunas síntesis más ambiciosas.

En este sentido, y conectando con lo anterior, cualquier historiador español que desee acercarse al fenómeno prostitucional deberá acudir a autores extranjeros para llenar los vacíos de la historiografía española ya que, aunque con estudios de sus propios países, pueden resultarnos altamente reveladores a la hora de interpretar determinados fenómenos relacionados con la prostitución ${ }^{6}$. Así mismo, con el objetivo de que este estado de la cuestión pueda comprenderse de la manera más correcta posible, se ha decidido dividirlo siguiendo una línea temática en vez de cronológica por entender que esta forma de organización puede ayudar el lector a la hora de observar con una mayor claridad los avances en determinados campos y las carencias en otros.

\section{Feminismo y prostitución}

La prostitución, como actividad mayoritariamente femenina, ha tenido a lo largo del tiempo una relación evidente con el feminismo. Hablando ya para los años que se pretenden analizar desde el punto de vista historiográfico, esta relación resultó muy importante y significativa en países del entorno español, sobre todo en Inglaterra (Josephine Butler), cuyo caso tendrá una influencia fundamental en los territorios europeos. Sin embargo, no existen apenas estudios en este sentido para el caso español, destacando por encima de todos el ya clásico de la hispanista inglesa Geraldine Scanlon ${ }^{7}$. En él, la autora dedica un capítulo entero al tema de la prostitución

\footnotetext{
${ }^{4}$ Rodríguez Solís, Enrique, Historia de la prostitución en España y América, 2 vols., Madrid, Biblioteca Nueva, 1892 y 1893.

${ }_{5}^{5}$ Del Moral, Carmen, La sociedad madrileña fin de siglo y Baroja, Madrid, Ediciones Turner, 1974. No obstante, esta tesis fue presentada en 1972.

${ }^{6}$ Me he centrado fundamentalmente en autores ingleses, americanos o franceses, aunque también he podido comprobar la existencia de obras relevantes para los casos alemán o ruso, por ejemplo.

${ }^{7}$ Scanlon, Geraldine, La polémica feminista en la España contemporánea (1868-1974), Madrid, Akal, 1986.
} 
y su vinculación con el movimiento feminista haciendo especial referencia a la corriente abolicionista, su surgimiento y desarrollo, así como su vinculación con España.

Por tanto, para llenar este vacío existente en la historiografía española es necesario recurrir, como ya he mencionado, a los estudios sobre el feminismo inglés y el movimiento abolicionista desencadenado en su seno. En este sentido, son fundamentales los estudios clásicos de Judith R. Walkowitz ${ }^{8}$, que aunque es verdad que se centran en un análisis sobre el feminismo y la sociedad victoriana, no es menos cierto lo interesantes que resultan sus alusiones a la sociedad en sí y a la integración del movimiento feminista en la misma.

Sin duda, también son de obligada lectura las primeras aportaciones del mundo estadounidense, es decir, los estudios de Vern Bullough y Bonnie Bullough ${ }^{9}$. Son pocos autores los que, antes de los años setenta, comenzaron a estudiar estos temas. Bien es cierto que, aunque sus obras fueron a veces muy generales, por ejemplo, el estudio de 1964 de Vern L Bullough, estos trabajos pioneros constituyen un referente ineludible. Respecto a la obra conjunta de ambos autores, estos realizan un recorrido por las formas de prostitución que ha habido a lo largo de la historia, centrándose en la evolución de la prostitución en Europa. Así mismo, los autores creían que la prostitución no podía ser entendida sin examinar el rol de la mujer en la sociedad, por tanto, los autores creyeron necesario proveer un análisis histórico, sociológico y antropológico acerca del fenómeno prostitucional. Por tanto, estos trabajos pudieron aportar a la historiografía española un marco de referencia y comparación con el resto de países occidentales.

Por la posible extrapolación del caso italiano al español, es relevante el trabajo de Mary Gibson ${ }^{10}$. La autora escribió una notable historia del sistema reglamentarista durante el periodo liberal, es decir, hasta la Primera Guerra Mundial, obviando la etapa fascista cuando la represión sobre las prostitutas y los controles a los que eran sometidas se intensificaron. Así pues, Gibson describe como las mujeres italianas ${ }^{11}$ de más de dieciséis años que violaban el toque de queda impuesto podían ser detenidas por la policía, ser sometidas a exámenes médicos vaginales y ser forzadas a trabajar en burdeles legales. Cualquier lector que se haya acercado al tema de la prostitución española en la etapa liberal podrá establecer paralelismos evidentes entre este relato y la situación en nuestro país en el mismo momento. Por tanto, el trabajo de esta autora resultó fundamental, no solo para la historiografía italiana, sino también para la española, al introducir en el campo de la historia académica el debate sobre la realidad diaria a la que

\footnotetext{
${ }^{8}$ Walkowitz, Judith, Prostitution and Victorian society: women, class, and the state, Cambridge, Cambridge University Press, 1980; “The politics of prostitution", en Signs: Journal of women in culture and society, 6 (1980), pp. 123-135; La ciudad de las pasiones terribles: narraciones sobre peligro sexual en el Londres victoriano, Madrid, Cátedra, 1995; "Vicio masculino y virtud feminista: el feminismo y la política sobre la prostitución en Gran Bretaña en el siglo XIX”, en Amelang, James y Nash, Mary, Historia y género: las mujeres en la Europa moderna y contemporánea, Valencia, Alfons el Magnànim, 1990.

${ }^{9}$ Bullough, Vern, The History of Prostitution, Nueva York, University Books, 1964. Bullough, Vern y Bullough, Bonnie, Women and Prostitution. A Social History, Buffalo, N.Y., Prometheus Books, 1987.

${ }^{10}$ Gibson, Mary, Prostitution and the State in Italy, 1860-1915, New Brunswick, Rutgers University Press, 1986.

${ }^{11}$ Es cierto que la autora utiliza, fundamentalmente, fuentes procedentes de los archivos policiales de la ciudad de Bolonia.
} 
eran sometidas las prostitutas, la privación de sus derechos civiles y de su libertad personal, conclusiones perfectamente extrapolables al caso español.

\section{La sexualidad como marco interpretativo}

En este tercer apartado, se han pretendido recopilar aquellas obras que tratan o estudian más de cerca el mundo de la sexualidad, no solo por ser objeto de estudio la específicamente femenina, sino por la atención que este tipo de trabajos prestan a aquellos tipos de sexualidad considerados como "anormales", como podía ser el caso de la homosexualidad y de la propia prostitución. Sin embargo, a pesar de la importancia de este tema, la bibliografía es especialmente escasa en lo que a la historiografía española se refiere en comparación con otros países. Así pues, las primeras publicaciones aparecen en los años 90 de la mano de Francisco Vázquez García $^{12}$, en solitario y, posteriormente, en colaboración con Andrés Moreno Mengíbar, muy marcados por la influencia de Michel Foucault y su historia de la sexualidad.

Sexo y Razón: Una genealogía de la moral sexual en España, siglos XVI-XX, fue un libro bien acogido por la comunidad historiográfica y que ha sido utilizado y citado por un buen número de historiadores. El libro se presentó en su momento en Madrid (con la colaboración de Félix Duque y Celia Amorós) y, como bien describe el propio Francisco Vázquez en un artículo retrospectivo sobre su obra, destacó por "considerar la sexualidad como una institución y no como un hecho natural, o abordarla como enclave y resultado de las relaciones de poder, en vez de contemplarla como lo reprimido por esas relaciones"13. En este sentido, la obra pasó a ser una guía fundamental para los que pretendían acercarse al campo de estudio de la sexualidad. Aunque los autores han continuado en esta línea de pensamiento, es cierto que la obra ha envejecido en ciertos aspectos y, como bien reconoce su autor, "mis propias indagaciones posteriores en este ámbito pasan por renunciar, en muchos aspectos, a lo que, con cierta ingenuidad, daba por sentado en $1997^{\prime \prime}$.

Aunque Vázquez y Moreno han seguido publicando a lo largo de los años estudios relacionadas con este tema, por ejemplo, el propio Francisco Vázquez García ${ }^{15}$ ha continuado

\footnotetext{
${ }^{12}$ Vázquez García, Francisco, "Historia de la sexualidad en España: problemas metodológicos y estado de la cuestión”, en Hispania: Revista española de historia, 194 (1996), pp. 107-103; Vázquez García, Francisco y Moreno Mengíbar, Andrés, Sexo y Razón: Una genealogía de la moral sexual en España, siglos XVI-XX, Torrejón de Ardoz, Akal, 1997.

${ }^{13}$ Es interesante la lectura del artículo que el propio autor ha escrito sobre su obra, de aparición reciente, analizando el impacto que tuvo la obra en su momento. Vázquez García, Francisco, "Sexo y Razón (1997), diecisiete años después”, Cuadernos de Historia Contemporánea, 40 (2018), p. 123, DOI «https://doi.org/10.5209/CHCO.60325». ${ }^{14}$ Vázquez García, Francisco, "Sexo y Razón (1997), diecisiete... op. cit., p. 123.

${ }^{15}$ Vázquez García, Francisco, "Figuras femeninas de la desviación sexual. España, 1850-1920", en Anuario de Hojas de Warmi, 15 (2010), pp. 1-36.
} 
realizando alguna investigación centrada en los diferentes tipos de conductas etiquetadas como "patológicas" en el contexto cultural de la Restauración, lo cierto es que las obras siguen siendo escasas.

El siguiente autor en este apartado es Jean-Louis Guereña ${ }^{16}$, el cual, mediante una recopilación de textos de los autores más destacados en el campo, ofrece al lector una interesante síntesis sobre los estudios que se están llevando a cabo en los últimos años en materia de sexualidad en España y que abarcan los siglos XIX y Xx ${ }^{17}$. Así mismo, el autor realiza una defensa de la historia de la sexualidad ya que opina que no hay nada extraño en que los historiadores se interesen directamente en esta temática, aunque encuentren dificultades a la hora de articular sus estudios. Mediante sus palabras, podemos observar cómo, en gran medida, este tema continúa siendo tabú.

También destaca el estudio de Raquel Osborne Verdugo ${ }^{18}$, la cual, mediante una recopilación de textos, la mayoría referentes al franquismo y la Transición, intenta introducir importantes elementos de análisis en este campo, además, este estudio es relativamente reciente. Aparte de esta obra, la autora ha ido publicando una serie de artículos muy interesantes que versan sobre la sexualidad en las cárceles femeninas franquistas, dándole a las prostitutas un papel central ${ }^{19}$.

Es relevante en igual medida el estudio realizado por Ramón Castejón Bolea ${ }^{20}$ que se ocupa del análisis del concepto de identidad sexual en Gregorio Marañón, principalmente, en los años 20. Así pues, en el mismo, se discute la teoría de la diferenciación sexual de Marañón y su defensa de la misión maternal de las mujeres.

\section{Prohibicionismo, reglamentarismo y abolicionismo}

La relación entre la prostitución y el derecho es evidente. En este sentido, los historiadores han indagado en este campo explicando los distintos corpus legales que las tres tendencias principales, prohibicionistas, reglamentaristas y abolicionistas, han elaborado en las distintas etapas históricas. En este apartado, nos encontramos con la obra pionera, ya mencionada, de

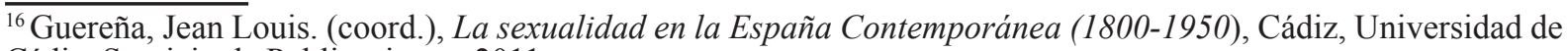
Cádiz, Servicio de Publicaciones, 2011.

${ }^{17}$ Este es sin duda el autor más importante de este Estado de la Cuestión por ser el escritor de la única monografía sobre el tema para época contemporánea. Se ha preferido tratar la totalidad de su obra en el último apartado de este artículo, por ser un ejemplo de trabajo transversal y totalizador.

${ }^{18}$ Osborne Verdugo, Raquel (coord.), Mujeres bajo sospecha. Memoria y sexualidad 1930-1980, Madrid, Editorial Fundamentos, 2012.

${ }^{19}$ Osborne Verdugo, Raquel, "De conflictos en torno a la sexualidad en las cárceles franquistas de mujeres a una crónica de la prostitución en la Guerra Civil”, en Martínez Guirao, Javier Eloy y Téllez Infantes, Anastasia (coords.), Cuerpo y cultura, Barcelona, Icaria, 2010, pp. 225-248.

${ }^{20}$ Castejón Bolea, Ramón, "Marañón y la identidad sexual: biología, sexualidad y género en la España de la década de 1920", en Arbor, 759 (2013), pp. 1-9.
} 
Carmen del Moral$^{21}$, su tesis doctoral, centrada en la novelística barojiana. En esta obra, la autora se introduce, concretamente en el capítulo $\mathrm{V}$, en el mundo de la prostitución madrileña, haciendo hincapié en las cuestiones reglamentaristas.

En este mismo sentido, y ya en los años 80, es de necesaria mención los trabajos llevados a cabo en Cataluña por Josep Clara ${ }^{22}$, centrados en la ciudad de Girona, y María Antonia Ferrer y Montserrat Duch, centradas en la ciudad de Tarragona. Ambos trabajos vuelven sobre las cuestiones relacionadas con el reglamentarismo como son las casas de prostitución toleradas y las leyes sanitarias. Para el caso de Barcelona, merece una mención aparte el trabajo de Mary $\mathrm{Nash}^{23}$ en el que la autora facilita sobremanera el acceso a ciertas fuentes primarias. No obstante, en lo referido a estudios locales, uno de los casos más investigados es la ciudad de Sevilla gracias a los trabajos, de nuevo, de Antonio Moreno Mengíbar y Francisco Vázquez García $^{24}$

Dejando los casos locales, nos encontramos con autores que han intentado realizar trabajos más de conjunto. En primer lugar, destaca la obra de José María Lidón ${ }^{25}$ debido a la importante labor que desarrolló publicando un gran número de reglamentos que encontró en el transcurso de sus investigaciones.

En segundo lugar, también son importantes las cuestiones analizadas por Matilde Cuevas y Luis Enrique Otero Carvajal ${ }^{26}$. Su artículo comienza con los debates parlamentarios en el transcurso de la discusión de la Ley contra Vagos y Ociosos (1820), y continúa con el análisis de los Códigos Penales de 1822, 1848 y 1870. Como podrá observarse, aunque sus investigaciones, que en un primer momento estuvieron muy centradas en la reglamentación, poco a poco, sobre todo por parte de Matilde Cuevas, han ido girando hacia lo social ${ }^{27}$.

Más reciente es el trabajo de Gemma Nicolás $\mathrm{Lazo}^{28}$ que, en su tesis doctoral, ha tratado de relacionar los discursos sobre la sexualidad con la reglamentación sobre la prostitución. No

\footnotetext{
${ }^{21}$ Del Moral, Carmen, La sociedad madrileña... op. cit.

${ }^{22}$ Clara, Josep, "Girona a mitjansegle XIX: les cases de tolerancia”, en Tercer Congrés d'Historia de la Medicina catalana, Lérida, 1981; Ferrer i Bosch, María Antonia, y Duch Plana, Montserrat, "Mesures de control i prevenciósanitaries a la ciutat de Tarragona: la prostitució a finals del segle XIX", en I Jornades d'Antropologia de la Medicina, Tarragona, Institut Català d'Antropologia, 1982.

${ }^{23}$ Nash, Mary, Mujer, familia y trabajo en España (1875-1936), Barcelona, Anthropos, 1983.

${ }^{24}$ Moreno Mengíbar, Andrés, y Vázquez, Francisco, "Biopolíticas del placer en España. Documentos sobre la prostitución en Sevilla: la reglamentación del siglo XIX", en Er: Revista de Filosofía, 11 (1990-1991), pp. 153-192; Moreno Mengíbar, Andrés y Vázquez, Francisco, "La prostitución reglamentada en Sevilla durante el siglo XIX", en Carrasco, Rafael (ed.), La prostitution en Espagne: de l'époque des Rois Catholiques à la IIe République, París, Les Belles Lettres, 1994, pp. 259-276; Moreno Mengíbar, Andrés, "Crisis y transformación de la prostitución en Sevilla (1885-1920)", en Aubert, Paul (dir.), Prostitución y sociedad en España siglos XIX y XX. Bulletin d'Histoire Contemporaine de l'Espagne, 25, Pau, Centre National de la Recherche Scientifique, 1997, pp. $119-134$

${ }^{25}$ Lidón, José María, "La reglamentación de la prostitución en España durante los siglos XIX y XX”, en Estudios de Deusto, 69 (1982), pp. 407-493.

${ }^{26}$ Cuevas, Matilde y Otero Carvajal, Luis Enrique, "Prostitución y legislación en el siglo XIX. Aproximación a la consideración social de la prostituta", en García-Nieto París, María Carmen (ed.), Ordenamiento jurídico y realidad social de las mujeres: Siglos XVI a XX. Actas de las IV Jornadas de Investigación Interdisciplinaria, Madrid, Universidad Autónoma de Madrid, 1986.

${ }^{27}$ Esta parte de su obra se abordará en el apartado correspondiente.

${ }^{28}$ Nicolás Lazo, Gemma, La reglamentación de la prostitución en el Estado español. Genealogía jurídico-feminista de los discursos sobre prostitución y sexualidad, Barcelona, Universidad de Barcelona, 2007.
} 
obstante, al provenir de un entorno jurídico, es normal que su investigación se centre más en estos aspectos. Así mismo, quien desee leer una visión de conjunto sobre los distintos debates que la prostitución ha generado a lo largo de la historia, con especial atención a los sistemas de los que trata este apartado, es recomendable la lectura de la tesis doctoral de María Francisca Corbalán Herrera ${ }^{29}$. Este trabajo, bastante reciente, ofrece una completa introducción histórica en su capítulo segundo analizando el tema desde la antigüedad clásica hasta los años 60/70 del siglo xx.

\section{El discurso médico. Estudios sobre higienismo}

Cualquier historiador español que quiera acercarse a la historia de la prostitución deberá acudir sin ningún género de dudas a la historia de la Medicina. Esta, tradicionalmente, se ha interesado por la historia del cuerpo, de la higiene, de las enfermedades venéreas, y, por lo tanto, por la historia de la sexualidad, profundamente ligada al fenómeno prostitucional ya que, siempre se ha vinculado o señalado a las prostitutas como núcleos de propagación de enfermedades (históricamente la sífilis, hoy en día el SIDA). En este sentido, es importante recalcar el papel jugado por las revistas Asclepio (Madrid), Dynamis (Granada) y Gimbernat (Barcelona), que han incluido entre sus páginas artículos claves para la cuestión, como se habrá podido observar en un gran número de las notas al pie de página de este artículo ${ }^{30}$.

En cuanto a los autores, en este campo destaca Ramón Castejón Bolea ${ }^{31}$ y su tesis doctoral sobre el combate en el seno de la medicina entre los prohibicionistas y los reglamentaristas, mayoría, que acabarán imponiendo su criterio y exportándolo al campo político. También es muy destacable el estudio de la hispanista francesa Claire Nicolle Robin ${ }^{32}$ en el que se analiza la posición frente a la prostitución de dos importantes revistas médicas durante la Restauración (El Siglo Médico y El Anfiteatro Anatómico Español).

A su lado aparecen los diversos artículos publicados por Rafael Alcaide González que tratan la introducción de la corriente higienista en el campo médico español centrándose, sobre

\footnotetext{
${ }^{29}$ Corbalán Herrera, María Francisca, Prostitutas de calle en Madrid en los inicios del nuevo milenio. Discursos y realidades sobre prostitución en el marco de las perspectivas de género, tesis doctoral, Universidad Complutense de Madrid, 2012.

${ }^{30}$ Por ejemplo, Casco Solís, Juan, "La higiene sexual en el proceso de institucionalización de la sanidad pública española", en Asclepio, 42 (1990), pp. 223-252; Guereña, Jean Louis, "Los orígenes de la reglamentación de la prostitución en la España contemporánea. De la propuesta de Cabarrús (1792) al Reglamento de Madrid (1847)", en Dynamis, 15 (1995), pp. 401-441.

${ }^{31}$ Castejón Bolea, Ramón, De la higiene de la prostitución a la lucha antivenérea: enfermedades venéreas y medicina social en España (1868-1936), tesis doctoral, Universidad de Granada, 1995. Con el paso de los años ha ido publicando artículos relacionados con su tesis, por ejemplo, Castejón Bolea, Ramón, "Las enfermedades venéreas y la regulación de la sexualidad en la España contemporánea”, en Asclepio, 56 (2004), pp. 223-242.

${ }^{32}$ Nicolle Robin, Claire, "La prostitución: El Siglo Médico/El A.A.E”, en Carrasco, Rafael (ed.), La prostitution en Espagne... op. cit., pp. 333-358.
} 
todo, en los médicos encuadrados en esta categoría pertenecientes a la ciudad de Barcelona ${ }^{33}$ y en el sistema reglamentarista de la misma ${ }^{34}$. Entre sus diversos trabajos, es sin duda de vital importancia aquel que versa sobre las distintas publicaciones médicas que tratan el tema del higienismo en España ${ }^{35}$.

No obstante, las publicaciones relacionadas con la medicina no solo versan sobre el higienismo y el sistema reglamentarista. En este sentido, resulta muy interesante el trabajo de Javier Bandrés, Eva Zubieta y Rafael Llavona ${ }^{36}$. En este estudio se analizan los trabajos sobre la psicología de la prostitución de tres personajes situados en instituciones claves durante la etapa franquista: Antonio Vallejo Nájera, Eduardo Martínez Martínez y Francisco J. Echalecu y Canino. Las investigaciones de estos tres autores los llevaron a caracterizar a las prostitutas como afectas innatas de psicopatía sexual, deficiencia mental y amoralidad. Este diagnóstico, así mismo, servía para justificar el internamiento de estas en cárceles especiales para su reforma.

\section{La prostitución y la sociedad}

Para el análisis correcto del fenómeno prostitucional es imprescindible la consulta de aquellos trabajos que tratan la prostitución desde el punto de vista social. A este respecto destaca de nuevo la anteriormente nombrada Matilde Cuevas $^{37}$, ya que en sus estudios se ilustra cómo la prostituta es observada con una mezcla de desconsideración, en particular, por parte de las clases dominantes, y de integración en los modos de vida y hacer cotidiano de los barrios bajos de la ciudad, formando comunidades homogéneas con fuertes lazos de solidaridad.

En este terreno, es también sobresaliente la obra de Rosa María Capel $^{38}$ en la que se tratan los problemas de marginalización que sufrían las mujeres dedicadas a esta actividad y la buena cantidad de dinero que a la vez aportaban al sistema. En este sentido, la autora cree que las autoridades pretendían mediante las diferentes medidas reducir la prostitución a unos límites

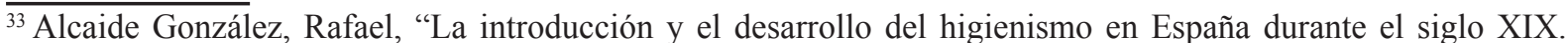
Precursores, continuadores y marco legal de un proyecto científico y social”, en Scripta Nova, 3 (1999), pp. 32-54; "La higiene de la prostitución en Barcelona. Una aproximación a los contenidos médico-sociales del higienismo en España en el siglo XIX", en Geo-crítica: Textos electrónicos (2000). «http://www.ub.edu/geocrit/pspestin.htm». ${ }^{34}$ Alcaide González, Rafael, "La reglamentación de la prostitución en la Barcelona de la Restauración (18701890)", en Hispania, 218 (2004), pp. 897-921.

${ }^{35}$ Alcaide González, Rafael, "Las publicaciones sobre higienismo en España durante el período 1736-1939. Un estudio bibliométrico", en Scripta Nova, 37 (1999), DOI «https://doi.org/10.1344/sn1999.3.112».

${ }^{36}$ Bandrés Javier et al., "Mujeres extraviadas: psicología y prostitución en la España de postguerra", Universitas Psychologica, 13 (2014), pp. 1668-1669.

${ }^{37}$ Cuevas, Matilde, “Aproximación a la consideración social de la prostitución madrileña”, en Otero Carvajal, Luis Enrique y Bahamonde, Ángel, Madrid en la sociedad del siglo XIX, Madrid, Comunidad de Madrid, Consejería de Cultura, 1986.

${ }^{38}$ Capel Martínez, Rosa María, "La prostitución en España: notas para un estudio socio-histórico", en Capel Martínez, Rosa María (coord.), Mujer y sociedad en España: 1700-1975, Madrid, Instituto de la Mujer, 1986.
} 
tolerables para poderla controlar. Por último, en este campo también destaca Aurora Rivière ${ }^{39}$ ya que trata y analiza con bastante profundidad la dimensión socio-histórica de la prostitución. El libro de esta autora versa sobre las instituciones encargadas en Madrid de recoger a las prostitutas. Así pues, apoyándose en el archivo de las Religiosas adoratrices, la autora logra aportar numerosos datos sobre la extracción socioprofesional de las prostitutas, su procedencia geográfica, sus motivaciones (sociales, económicas, culturales), así como la vida de las mismas dentro de estas instituciones.

Por último, también podemos encontrar esta aproximación sociológica en el estudio que sobre Córdoba hace Fernando López Mora ${ }^{40}$. En este trabajo, el autor insiste en la necesidad de profundizar en aspectos como determinar la procedencia social de las prostitutas. En esta misma línea de investigación en torno a la procedencia social, se sitúan otros trabajos como el de Carmen Sarasúa ${ }^{41}$ que dedica una monografía al servicio doméstico en Madrid desde el siglo XVIII hasta 1868, exponiendo en una parte de la misma, las conexiones entre este y la prostitución. En esta misma estela se sitúa Josette Borderies-Guereña ${ }^{42}$.

Así mismo, dentro de este apartado, merece la pena nombrar los trabajos concernientes a la etapa franquista que, aunque son escasos, pueden abrirnos interesantes puertas. Sin duda, como libro de cabecera situaríamos el trabajo de Mirta Núñez Díaz-Balart ${ }^{43}$, en el que nos narra cómo la represión y la miseria de la larga posguerra arrojaron a miles de mujeres a la prostitución para lograr sobrevivir. Esta prostitución era de dos tipos fundamentalmente, reglamentada ${ }^{44} \mathrm{y}$ clandestina, ya que muchas mujeres pretendían evitar los exhaustivos controles sanitarios a los que eran sometidas en los burdeles. No obstante, si decidían practicar esta actividad por libre, se exponían a las detenciones gubernativas, paso previo para su envío a cárceles especiales o reformatorios con el objetivo de reformar su conducta (Obra de Redención de Mujeres Caídas). Allí eran educadas y adoctrinadas en las normas morales y políticas del nuevo régimen.

En este sentido, podemos observar como Núñez Díaz-Balart nos apunta a que la dimensión social del problema se hallaba en la pobreza, sin embargo, las autoridades y su preocupación no estaba relacionada con la misma, sino con esta actividad que atacaba la "moral" del régimen y con la elevada propagación de las enfermedades venéreas. Así pues, a lo largo de los años, esta autora ha ido publicando nuevos trabajos al respecto ${ }^{45}$.

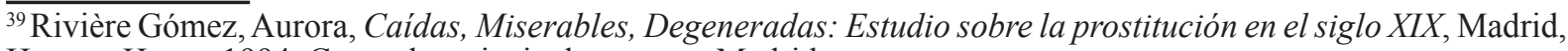
Horas y Horas, 1994. Centrado, principalmente, en Madrid.

${ }^{40}$ López Mora, Fernando, "La prostitución cordobesa durante la segunda mitad del siglo XIX: reglamentarismo y aproximación sociológica", en Carrasco, Rafael (ed.), La prostitution en Espagne... op. cit., pp. 277-305.

${ }^{41}$ Sarasúa, Carmen, Criados, nodrizas y amos. El servicio doméstico en la formación del mercado de trabajo madrileño (1758-1868), Madrid, Siglo Veintiuno, 1994.

${ }^{42}$ Borderies-Guereña, Josette, “Trabajo doméstico y prostitución”, en Historiar. Revista trimestral de historia, 2 (1999), pp. 24-34.

${ }^{43}$ Núñez Díaz-Balart, Mirta, Mujeres caídas: prostitutas legales y clandestinas en el franquismo, Madrid, Oberón, 2003.

${ }^{44}$ Hasta 1956 , cuando se procederá a su abolición.

${ }^{45}$ Núñez Díaz-Balart, Mirta, «Mujeres caídas. El problema de la prostitución en la posguerra desde la propaganda franquista", en García Galindo, Juan Antonio et al., (coords.), La comunicación social durante el franquismo, Málaga, Diputación Provincial de Málaga, 2002, pp. 221-230. En cuento a sus trabajos más recientes: "Los muros
} 
Siguiendo con el franquismo, Jean Louis Guereña también tiene una serie de artículos relativos a esta etapa, aunque, sin duda, es el periodo al que menos atención le ha prestado, volcándose sobre todo en el siglo XIX. Sin embargo, su línea discursiva coincide prácticamente en su totalidad con la autora mencionada anteriormente volviendo a situar como problemas centrales la pobreza y las enfermedades venéreas ${ }^{46}$.

También merece ser mencionado el trabajo de Assumpta Roura ${ }^{47}$. En él, la autora edita y publica un documento redactado por el Patronato para la Protección de la Mujer en 1943, una memoria que dicha entidad realizó y tituló como Informe sobre la moralidad pública en España. Allí se reconocían las competencias del Estado respecto a la salvaguarda del orden moral y se aducían diversas razones por las cuales se justifica la intervención estatal en este campo, de esta manera, se establecía como principal objetivo recuperar la moral anterior a la experiencia republicana. Así pues, el informe habla de estas "mujeres caídas", entre las que se encontraban las prostitutas por ser, especialmente, mujeres que no encajaban en el nuevo modelo de género que el franquismo pretendía imponer. En este sentido, Assumpta Roura, por su carácter netamente represivo y por la época en la que surgió (1941), la definió como una "institución de corte fascista".

Por último, para el franquismo destacan una serie de autores, no tan centrales como los anteriores, pero igualmente merecedores de mención. Así nos encontramos con el estudio de Lucía Prieto Borrego ${ }^{48}$. Esta autora, una de las primeras historiadoras en acudir a las memorias del Patronato para la Protección de la Mujer, analiza la situación de la prostitución en Andalucía. Se trata de uno de los pocos estudios destinados por completo a este tema, aunque sea de carácter regional. En este sentido, y aunque está referido al período comprendido hasta la aprobación del decreto abolicionista impulsado por los sectores católicos en 1956, Lucía Prieto mantiene que las memorias del mencionado Patronato están marcadas por una clara ideología "nacionalcatólica", en la que se identifica como un todo a la mujer con la moral. Por tanto, podemos ver cómo la autora defiende que el Patronato estaba marcado por una ideología de este tipo, al contrario de lo mantenido por Assumpta Roura, que define a la organización como fascista.

Continuando con este punto de vista social, es importante destacar el trabajo de Rafael Torres ${ }^{49}$, concretamente su capítulo VI ("El mercado negro. Prostitución”). Como dice el propio autor en la introducción de su obra "el régimen surgido de la sublevación contra la legalidad

caídos de la decencia. La prostitución en el franquismo de posguerra", en Egido León, Ángeles y Montes Salguero, Jorge J. (coords.), Mujer, franquismo y represión: una deuda histórica, Madrid, Sanz y Torres, 2018, pp. 273-288.

${ }^{46}$ Guereña, Jean-Louis, "Marginación, prostitución y delincuencia sexual: la represión de la moralidad en la España franquista (1939-1956)", en Agustí i Roca, Carme et al., (coords.), Pobreza, marginación, delincuencia y políticas sociales bajo el franquismo, Lleida, Universidad de Lleida, 2005, pp. 165-194; Algún trabajo más reciente: "Prostitución y franquismo. Vaivenes de una política sexual", en Osborne, Raquel (ed.), Mujeres bajo sospecha... op. cit., pp. 143-164.

${ }^{47}$ Roura, Assumpta (ed.), Un inmenso prostíbulo. Mujer y moralidad durante el franquismo, Barcelona, Editorial Base, 2005.

${ }_{48}$ Prieto Borrego, Lucía, "La prostitución en Andalucía durante el primer franquismo", en Baetica, 28 (2006), pp. $665-687$.

${ }^{49}$ Torres, Rafael, El amor en tiempos de Franco, Madrid, Oberón, 2002. 
republicana y la democracia no tuvo, en principio, otro norte que la represión: (...) actúo con saña contra todas las expresiones de la libertad, y el amor, el sexo". Así pues, Torres analiza la prostitución englobada dentro de un contexto más amplio en el que se tratan temas tan cruciales para la época como el matrimonio, la homosexualidad, la virginidad o la tardía revolución sexual.

Entre los últimos trabajos para este mismo periodo destaca el de Carmen Guillén Lorente en el que nos habla de cómo el decreto abolicionista de 1956, solo "consiguió empeorar una situación caracterizada, cada vez, más por la clandestinidad y la peligrosidad. La etapa abolicionista dio pasó a medidas de corte claramente prohibicionista que, en la práctica, sólo sirvieron para precarizar la vida de las prostitutas" ${ }^{50}$.

\section{Sexualidad y anarquismo}

En séptimo lugar, destacan aquellas obras que han tratado el discurso anarquista, sin duda uno de los más alternativos en lo que se refiere al panorama político español. Los primeros trabajos fueron los realizados por Mary $\mathrm{Nash}^{51}$. En ellos, la autora se introduce en el mundo de las mujeres anarquistas y el proyecto de los llamados "liberatorios de prostitución". En este sentido, también son muy importantes los trabajos de José Álvarez Junco ${ }^{52}$ por tratar, de un modo introductorio, en su capítulo "Feminismo, familia, amor libre" los debates acerca de la mujer y el trabajo, la sindicalización femenina, el papel de la familia en la sociedad burguesa y la cuestión del amor. En este mismo plano se sitúan los trabajos elaborados por Joaquín Romero Maura $^{53}$.

En este mismo campo, es necesario mencionar a aquellos autores que han prestado una especial importancia a la prensa, relacionándola con temas que entran en conexión con la mujer como la prostitución o la sexualidad. En este grupo se encuentra el estudio ya clásico de Gerard Brey ${ }^{54}$ donde se nos muestra cómo el anarquismo se señala en principio solidario con las prostitutas pero no hace nada para que los obreros dejen de frecuentarlas. En segundo lugar, nos encontramos con el trabajo de María Ángeles García-Maroto ${ }^{55}$ que, aunque se centra en

\footnotetext{
$\overline{{ }^{50} \text { Guillén Lorente, }}$ Carmen, "De la prostitución reglamentada al ocaso del burdel. Una aproximación legislativa a la prostitución durante la etapa franquista", en González Madrid, Damián Alberto et al., (coords.), La Historia, lost in translation?, Universidad de Castilla-La Mancha, 2017, pp. 527-536. La cita corresponde a la página 535. ${ }^{51}$ Nash, Mary, Mujeres Libres, España 1936-1939, Barcelona, Tusquets, 1975.

${ }_{52}$ Álvarez Junco, José, La ideología política del anarquismo español (1868-1910), Madrid, Siglo Veintiuno, 1976.

${ }^{53}$ Romero Maura, Joaquín, La rosa de fuego: republicanos y anarquistas. La política de los obreros barceloneses entre el desastre colonial y la semana trágica, 1899-1909, Barcelona, Ediciones Grijalbo, Barcelona, 1975.

${ }^{54}$ Brey, Gerard, "La prostitution dans la presse anarchiste espagnole (1881-1907)", en Carrasco, Rafael (ed.), La prostitution en Espagne... op. cit. pp. 345-357.

${ }_{55}$ García-Maroto, María Ángeles, La mujer en la prensa anarquista: España 1900-1936, Madrid, Fundación Anselmo Lorenzo, 1996.
} 
las mujeres de manera general, resulta interesante por analizar los debates realizados por las mismas en el seno del anarquismo. En tercer lugar, y de más reciente publicación, destaca el trabajo de Xavier Díez ${ }^{56}$ donde se analizan los diferentes aspectos del discurso del amor libre, es decir, sus bases teóricas, sus mecanismos de información y transmisión y el contenidos de sus planteamientos. También es de interesante consulta el trabajo de Richard Cleminson ${ }^{57}$ ya que está orientado hacia el tema de la sexualidad.

\section{Las visiones más totalizadoras y transversales}

Al margen de toda esta clasificación temática, me ha parecido adecuado recoger en un apartado específico las obras que tratan el tema de la prostitución de una manera totalizadora, ya que no solo abarcan los siglos XIX y xx, sino que además constituyen un hito por tratar los diferentes campos relacionados con la prostitución.

Así pues, en este grupo se encuentra el primer congreso sobre la historia de la prostitución en España en la época moderna y contemporánea ${ }^{58}$ (desde los Reyes Católicos hasta la II República). Este trabajo es, sin duda, importante por reunir a algunos especialistas bastante sobresalientes y por tratar diversos temas como el reglamentarismo en el siglo XIX y xx, el discurso médico, la prensa anarquista o la literatura. En segundo lugar, destaca el ejemplar dedicado a la prostitución en España por El Bulletin d'Histoire Contemporaine de l'Espagne ${ }^{59}$ en el que, como en el caso anterior, se tratan diversos temas desde el punto de vista de distintos especialistas.

Por último, pero no menos importante, los distintos trabajos publicados por Jean-Louis Guereña, ya mencionado en varias partes de este artículo. Este hispanista francés ha sido, a lo largo de este tiempo, uno de los únicos historiadores que ha publicado diferentes estudios que cubren un espectro muy amplio. De esta manera, ha logrado abracar el sistema reglamentarista ${ }^{60}$, el desarrollo de las corrientes abolicionistas ${ }^{61}$, la promulgación de leyes por parte de los distintos

\footnotetext{
${ }^{56}$ Díez, Xavier, Utopía sexual a la premsa anarquista de Catalunya: la revista Ética-Iniciales (1927-1937), Barcelona, Pagès Editors, 2001.

${ }^{57}$ Cleminson, Richard, Anarquismo y sexualidad en España, 1900-1939, Cádiz, Servicio Publicaciones de la Universidad de Cádiz, 2008.

${ }^{58}$ Carrasco, Rafael (ed.), La prostitution en Espagne... op. cit. El congreso tuvo lugar en 1991.

59Aubert, Paul (dir.), Prostitución y sociedad... op. cit.

${ }^{60}$ Guereña, Jean Louis, "Los orígenes de... op. cit.

${ }^{61}$ Guereña, Jean Louis, "La masonería española frente a la prostitución durante la Restauración", en Ferrer Benimeli, José Antonio, La masonería española en el 2000: una revisión histórica, vol. 2, Zaragoza, Gobierno de Aragón, Departamento de Cultura y Turismo, 2001, pp. 641-662.
} 
gobiernos $^{62}$, el discurso médico, el trasfondo social ${ }^{63}$ o los diferentes estudios locales ${ }^{64}$, en algunas ocasiones, sobre territorios que no habían sido explorados hasta la fecha como, por ejemplo, el sistema reglamentarista instaurado en Zaragoza ${ }^{65}$.

No obstante, por encima de todos estos trabajos sobresale su monografía ${ }^{66}$, la única para este tema, en la que se lleva a cabo una gran síntesis para la edad contemporánea en España. El autor muestra la evolución desde finales del siglo XVIII hasta la actualidad del mundo prostitucional, comenzando con el abolicionismo existente en la España del Antiguo Régimen, y cómo las ideas ilustradas y la implantación del estado liberal permitieron el paso al modelo reglamentarista a mediados de la centuria decimonónica. Guereña explica de manera muy detallada este sistema, las condiciones a las que estaban sometidas las prostitutas y su vinculación constante con las enfermedades venéreas. Paralelamente a esto, el autor comienza a explicar el surgimiento de la corriente abolicionista en el seno del feminismo inglés (Josephine Butler) y cómo estas ideas llegaron a España de mano de los masones, los protestantes y los republicanos a finales del siglo XIX. Aunque destacadas feministas españolas como Concepción Arenal o Margarita Nelken apostarán por estas ideas, no será hasta la II República cuando estas encuentren una aplicación legal. El autor continúa explicando la situación en la Guerra Civil y el franquismo, llegando hasta nuestros días. Como puede observarse, el autor realiza un ingente esfuerzo de síntesis, recopilando una gran cantidad de datos y estudios en una única obra que está destinada a ser el libro de cabecera de cualquiera que quiera acercarse a este tema de investigación en la Edad Contemporánea. Sin duda, si hubiera que destacar un especialista entre todos los nombrados en este artículo sería este.

No obstante, Jean-Louis Guereña no ha dejado de ahondar en este tema y recientemente ha publicado un nuevo trabajo imprescindible ${ }^{67}$. Este autor versado en la materia y entendiendo que la sexualidad de una determinada sociedad tiene mucho que revelar acerca de la misma, nos ofrece una recopilación revisada y actualizada de los trabajos de investigación que el autor ha acometido en las últimas décadas. En este sentido, aunque Guereña no solo toca el tema de la prostitución, sobre ella versa una buena parte del volumen, concretamente su parte segunda. Bien es cierto, que quien haya seguido la carrera de este hispanista encontrará escasas novedades en esta parte.

\footnotetext{
${ }^{62}$ Por ejemplo, Guereña, Jean Louis, "Prostitución, Estado y Sociedad en España: La reglamentación de la prostitución bajo la monarquía de Isabel II (1854-1868)", en Asclepio, 49 (1997), pp. 101-132.

${ }^{63}$ Por ejemplo, Guereña, Jean Louis, "El burdel como espacio de sociabilidad”, en Hispania, 214 (2003), pp. 551570.

${ }^{64}$ Guereña, Jean Louis, "Prostitución, Estado y Sociedad en España bajo la monarquía de Isabel II: El caso gaditano", en Trocader. Revista de historia moderna y contemporánea, 10-11 (1998-1999), pp. 119-144.

${ }^{65}$ Guereña, Jean Louis, "La Policía Sanitaria de las mujeres públicas (Zaragoza, 1845). Los orígenes del reglamentarismo en la España contemporánea”, en Revista de Historia Jerónimo Zurita, 74 (1999), pp. 7-26.

${ }^{66}$ Guereña, Jean Louis, La prostitución en la España contemporánea, Marcial Pons, Madrid, 2003.

${ }^{67}$ Guereña, Jean-Louis, Detrás de la cortina: el sexo en España (1790-1950), Madrid, Cátedra, 2018.
} 
9. Muchos caminos por recorrer

Como ha podido intuirse a lo largo de las líneas anteriores, el panorama historiográfico está caracterizado por una profunda desigualdad en el tiempo que abarcan las investigaciones, los lugares que analizan y los temas que tratan. En el primer caso, es evidente que la etapa más estudiada es la segunda mitad del siglo XIX, mientras que los primeros años del siglo xx han recibido, hasta la fecha, muy poca atención. En lo referente a la II República y la Guerra Civil es posible la localización de algunos estudios, aunque desde puntos de vista muy concretos como, por ejemplo, el anarquismo. En cuanto a la etapa franquista, comienza a haber algunos estudios muy interesantes, sin embargo, aún nos quedan cosas por entender en lo relativo a la fragua de la corriente abolicionista que los sectores católicos del régimen impulsaron desde casi los primeros momentos de la posguerra hasta la consecución del decreto de 1956.

En el segundo caso, si uno se fija en las publicaciones y las ciudades y territorios que tratan, podrá darse cuenta de que las zonas que más atención han recibido han sido Andalucía, Madrid y Cataluña. La primera ha sido producto del esfuerzo de apenas tres historiadores que se han ocupado de los casos de Sevilla, Córdoba o Cádiz. La segunda, ha sido bastante bien estudiada desde distintas aproximaciones que la convierten en una de las zonas más avanzadas en lo que a investigación se refiere. La tercera podemos afirmar que es la Comunidad Autónoma en la que más estudios se han realizado, no solo tratando las grandes capitales sino también las ciudades de tamaño medio. Sin embargo, este hecho también señala que el resto del territorio español adolece de una falta evidente de estudios, es cierto, que en algunos lugares se han comenzado a publicar trabajos en este sentido como Galicia, pero también es verdad que hay lugares que son un completo desierto como es el caso de Aragón, y, especialmente, de Zaragoza a pesar de ser la ciudad en la que se encontró, por parte del propio Guereña, el primer reglamento (1845) sobre prostitución para el siglo XIX español.

En el tercer caso, ha quedado de manifiesto que, mientras que el análisis jurídico, el discurso médico o el punto de vista social han llamado la atención de un buen número de historiadores que han realizado interesantísimas aportaciones, hay otros campos que no han tenido el mismo tratamiento como es el caso de la sexualidad o la relación con el feminismo en el que apenas hay un puñado de estudios y alguno de ellos bastante antiguos. En este sentido, no se debe entender esta afirmación como una crítica a los Historiadores del Derecho y la Medicina, cuyo punto de vista es ciertamente fundamental a la hora de entender determinados fenómenos, sino como un intento de señalar aquellos campos que necesitan ser investigados para poder avanzar en el conocimiento del fenómeno prostitucional.

Siguiendo con este hilo argumental, es cierto que algunas de las evidentes diferencias entre territorios, periodos históricos y temas puede ser explicada por la presencia de 
historiadores interesados en el tema en determinados lugares, sin embargo, otras diferencias requieren una mayor profundización. En lo relativo a los vacíos historiográficos para el siglo $\mathrm{xx}$ y, especialmente, para la etapa franquista, muchos historiadores han señalado y denunciado los obstáculos que a menudo se encuentra el investigador a la hora de acceder a la información documental. Esto se vuelve especialmente sangrante si la Iglesia y sus diversas organizaciones entran en juego (las Oblatas, por ejemplo) y si la etapa cronológica que abarca la investigación es la dictadura. A estas dificultades se une la realidad de que muchos fondos documentales aún no hayan pasado a los archivos históricos correspondientes; permanecen en las dependencias de los organismos que los generaron, donde las facilidades para su consulta son escasas o bien han "desaparecido". Más allá de estas dificultades para acceder a las fuentes, es cierto que acercarse a la historia de la prostitución desde un punto de vista social, analizando trayectorias de vida y reconstruyendo el día a día de las mismas, es una de las tareas más difíciles debido a la dificultad para encontrar a estas mujeres en los documentos históricos. Sin duda, los archivos policiales, allí dónde se conserven, parecen un buen punto de partida al que acercarse.

A todo ello, se añade la consideración de la historia de la prostitución-sexualidad como una historia de segunda clase. Durante mucho tiempo los historiadores "serios" se han dedicado a "los temas importantes", mientras que el resto insistían en parcelas de la historiografía apenas exploradas. Aunque es cierto que en los últimos años esto parece estar cambiando, no es menos cierto que estos temas de investigación siguen ocupando un puesto secundario en lo referido al entendimiento del pasado.

Para terminar, es necesario añadir que, a lo largo de la historia y aún hoy en día, la prostituta ha sido categorizada como la "otra", el polo opuesto a la "mujer verdadera" (madreesposa). En este sentido, a lo largo del tiempo se han ido construyendo una serie de discursos destinados, en primer lugar, a la estigmatización de este colectivo y, en segundo lugar, a la justificación del intervencionismo social. Así pues, y como hemos podido intuir en este estado de la cuestión, la prostituta era señalada como culpable de un delito doble, contra la moral (su actitud contraria a los roles de género establecidos podía contagiar al resto del cuerpo social) y contra la salud pública (su identificación constante con las enfermedades de transmisión sexual). Esta identificación entre moral-higiene-orden social traspasa todo el siglo xix y continúa hasta nuestros días. Por tanto, cualquiera que quiera acercarse al estudio de la prostitución deberá abstraerse de los prejuicios y estereotipos que rodean a las prostitutas; deberá dejar de verlas como mujeres víctimas y esclavas, y pasar a observarlas como sujetos con agencia. 